\title{
Time-Consistent Management of a Liquidity Trap with Government Debt
}

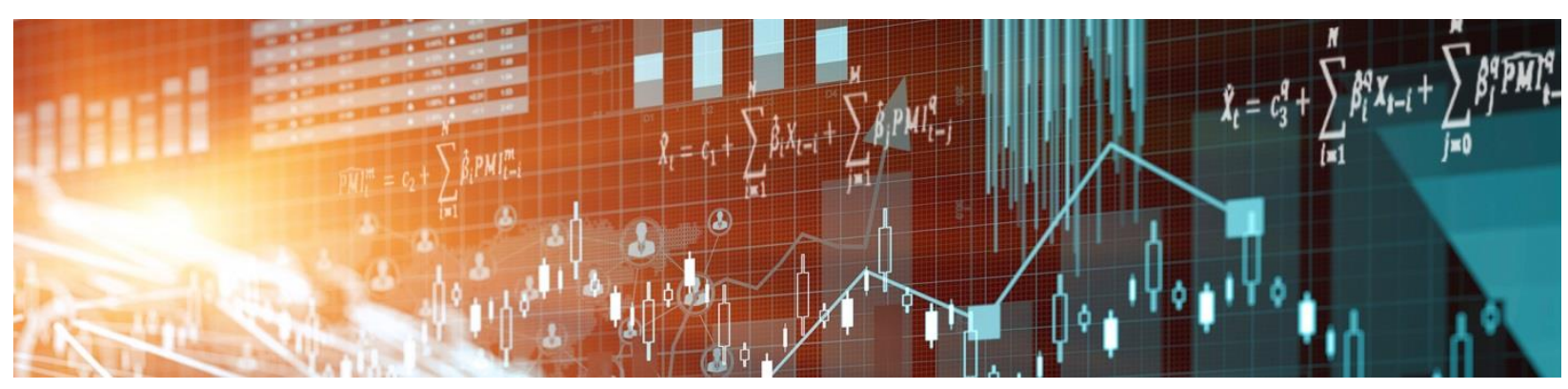

by Dmitry Matveev 
Bank of Canada Staff Working Paper 2018-38

July 2018

\title{
Time-Consistent Management of a Liquidity Trap with Government Debt
}

\author{
by \\ Dmitry Matveev \\ Canadian Economic Analysis Department \\ Bank of Canada \\ Ottawa, Ontario, Canada K1A 0G9 \\ dmatveev@bankofcanada.ca
}




\section{Acknowledgements}

This is a revised version of the paper that was previously circulated under the title "TimeConsistent Management of a Liquidity Trap: Monetary and Fiscal policy with Debt." The views expressed in this paper are those solely of the author, and no responsibility for them should be attributed to the Bank of Canada. I am indebted to Stefano Gnocchi, Albert Marcet, and Francesc Obiols. For useful discussions I thank Klaus Adam, Jeffrey Campbell, Martin Ellison, Jordi Galí, Yuliya Kulikova, Sarolta Laczó, Hannes Mueller, Rigas Oikonomou, Johannes Pfeifer, Guillem Pons Rabat, Pontus Rendahl, Sebastian Schmidt, and Arnau Valladares-Esteban. All remaining errors are mine. 


\begin{abstract}
This paper studies optimal discretionary monetary and fiscal policy when the lower bound on nominal interest rates is occasionally binding in a model with nominal rigidities and long-term government debt. At the lower bound it is optimal for the government to temporarily reduce debt. This decline stimulates output, which is inefficiently low during liquidity traps, by lowering expected real interest rates following the lift-off of the nominal rate from the lower bound. Away from the lower bound, the long-run level of government debt increases with the risk of reaching the lower bound. The accumulation of debt pushes up inflation expectations so as to offset the opposite effect due to the lower bound risk.
\end{abstract}

Bank topics: Monetary policy; Fiscal policy

JEL codes: E52, E62, E63

\title{
Résumé
}

Cette étude s'intéresse aux politiques monétaire et budgétaire optimales et discrétionnaires lorsque la valeur plancher des taux d'intérêt nominaux se fait, à l'occasion, contraignante. Un modèle intégrant des rigidités nominales et une dette publique de long terme est utilisé à cette fin. Lorsque les taux atteignent leur valeur plancher, une réduction temporaire de la dette publique est optimale. Cette réduction stimule en effet la production - qui est trop basse comparativement à l'optimum social en présence d'une trappe à liquidité - en diminuant les taux d'intérêt réels attendus après le relèvement des taux nominaux. Lorsque les taux nominaux sont éloignés de leur valeur plancher, le niveau optimal de dette publique de long terme est d'autant plus élevé que le risque d'atteindre la valeur plancher est important. L'accumulation de la dette publique fait augmenter les attentes d'inflation, ce qui compense la diminution des attentes attribuable à ce risque.

Sujets : Politique monétaire; Politique budgétaire

Codes JEL : E52, E62, E63 


\section{Non-Technical Summary}

Since the Great Recession, many central banks in advanced economies have been constrained by the zero lower bound on nominal interest rates. This fact generated a discussion about alternative policy tools for stabilizing business cycles, such as unconventional monetary policy or fiscal policy. This paper focuses on the latter.

The main objective of this paper is to describe the optimal use of government debt when the lower bound is occasionally binding. Should policymakers accumulate government debt during a liquidity trap? Should the risk of a liquidity trap affect debt issuance away from the zero lower bound? I address these questions in a model economy with costly price adjustment and demand shocks, where benevolent policymakers maximize social welfare by choosing the short-term nominal interest rate, government spending, and a labor income tax.

The key innovation of this paper is to allow for government debt with long maturity in line with the one observed in the data across advanced economies. The literature so far has focused on short-term debt that matures every quarter. The first result in the current paper is that long-run government debt increases with the risk of reaching the zero lower bound. Debt accumulation acts as a buffer against the zero lower bound risk and its optimal level is higher than in an economy that is not subject to such risk. The second result is that when the zero lower bound is binding, the government temporarily reduces debt. This temporary decline stimulates aggregate demand by lowering future expected real interest rates. After the nominal interest rate lifts off from the lower bound, the government re-accumulates debt back to its steady-state level.

The main contribution of this paper is to show that accumulating debt during a liquidity trap may or may not be optimal depending on its maturity. While Eggertsson (2006) and Burgert and Schmidt (2014) show that it is desirable to increase debt in an economy with short-term bonds, I find the opposite if the model is calibrated to match the observed maturity of the government's liabilities.

The findings in this paper suggest that debt maturity is an important factor in designing monetary and fiscal policy. A fruitful avenue for future research would be to re-examine conventional prescriptions of a monetary-fiscal policy mix depending on the maturity of government debt. 
Economically, it would be preferable to have more proactive fiscal policies and a more balanced monetary-fiscal mix when interest rates are close to zero.

Bernanke (2016)

\section{Introduction}

In December 2008, in the midst of the Great Recession, the Federal Reserve lowered the federal funds rate to almost zero. The policy rate then remained near zero for seven consecutive years. The European Central Bank, the Bank of Japan, and the central banks in other smaller advanced economies are currently experiencing liquidity traps. The lower bound on conventional monetary policy instruments has spurred a discussion of alternative policy tools for stabilizing business cycles, such as unconventional monetary policy or fiscal policy. This paper focuses on the latter.

Most of the literature studying optimal fiscal policy in a liquidity trap limits the analysis to short-term government debt, which is typically assumed to mature every quarter (see, e.g., Eggertsson and Woodford (2006), Eggertsson (2006), Burgert and Schmidt (2014), and Nakata (2017)). In practice, however, the average maturity of government debt across G-7 countries before the Great Recession varied from four to 14 years; see Greenwood et al. (2014). The current paper fills this gap and shows that long-term debt affects policy prescriptions both qualitatively and quantitatively.

I characterize the optimal monetary-fiscal policy mix in an economy with costly price adjustment where the zero lower bound (ZLB) on the nominal interest rate occasionally binds following an adverse aggregate demand shock. The short-term nominal interest rate is the only monetary policy instrument, while fiscal instruments are limited to government spending and a labor income tax, as in Lucas and Stokey (1983). I assume that all policy instruments are chosen by a benevolent government that maximizes social welfare under discretion. ${ }^{1}$ These assumptions allow me to disregard policy coordination issues, and to exclude the use of time-inconsistent promises such as in the case

\footnotetext{
${ }^{1}$ The classic inflation bias in the deterministic steady state is assumed to be eliminated with a lump-sum tax that finances a constant employment subsidy.
} 
of forward guidance. Both of these issues, though interesting, lie outside of the scope of my analysis. The focus here is rather the strategic use of debt as a tool to credibly affect the policy of future government and, through this channel, current expectations about a future policy mix. ${ }^{2}$

The first result is that when the ZLB is binding, the government runs down debt and then re-accumulates it by cutting tax rates after the nominal interest rate lifts off. ${ }^{3}$ Lower future tax rates reduce the expected marginal cost of production and inflation, thereby creating an endogenous trade-off between inflation and the output gap. This trade-off resembles the one following a traditional negative cost-push shock; see Clarida et al. (1999). The optimal expected monetary policy response is to lower the nominal interest rate enough to reduce the real rate. Since households correctly anticipate future monetary policy, the temporary decline in government debt stimulates aggregate demand by lowering expected real interest rates.

The second result is that long-run government debt increases with the risk of reaching the ZLB. Even in the absence of realized demand shocks, the mere risk of hitting the ZLB reduces inflation expectations, curbing current inflation as first documented by Adam and Billi (2007) and Nakov (2008). I show that this deflationary effect can be mitigated by accumulating more debt. In fact, the corresponding increase in taxes, required to finance the higher level of debt, generates inflation expectations and permanently raises the nominal interest rate. Through this mechanism, debt accumulation acts as a buffer against the ZLB risk and its optimal level is higher than in an economy that is not subject to such risk. Under the baseline calibration, the steady-state market value of debt measured as a fraction of annual GDP increases by 32 percent, as compared to the analogous economy without demand shocks.

The current paper contributes to the literature as follows. First, it shows that accumulating debt during a liquidity trap may or may not be optimal depending

\footnotetext{
${ }^{2}$ The role of government debt in affecting expectations of fiscal policy, while asbtracting from monetary policy and nominal rigidities, is studied in Debortoli and Nunes (2012).

${ }^{3}$ Government debt declines amid an increase in both government spending and labor tax. Responses of tax rate and government spending are consistent with earlier findings in Eggertsson and Woodford (2006), Werning (2011), Schmidt (2013) and Nakata (2017).
} 
on its maturity. While Eggertsson (2006) and Burgert and Schmidt (2014) show that it is desirable to increase debt in an economy with short-term bonds, I find the opposite if the model is calibrated to match the observed maturity of government's liabilities. ${ }^{4}$ In a liquidity trap, the effects of debt accumulation on aggregate demand crucially depend on how monetary policy is expected to be conducted after the lift-off and the resulting path of the real interest rate. In turn, the optimal response of monetary policy to government debt depends on its maturity. If debt is short-term, maintaining an accommodative monetary policy stance is desirable: at the cost of generating inflation, expansionary monetary policy has the benefit of mitigating the hike in distortionary tax rates needed to finance the outstanding level of a government's obligations. In fact, lower interest rates expand the tax base by boosting aggregate demand and increase the price of newly issued government bonds. The latter effect, which is predominant in shaping the fiscal benefits of a monetary expansion, becomes weaker the longer the maturity of debt; see Matveev (2016). Thus, in an economy with long-term debt the inflationary costs of monetary accommodation outweigh its fiscal benefits and, consequently, during a liquidity trap, debt consolidation is optimal.

Second, this paper shows that the ZLB risk has implications for optimal fiscal policy even when the nominal interest rate is positive. The effects of the ZLB risk on optimal monetary and fiscal policy have been previously investigated in the absence of government debt. Monetary policy has been shown to be more accommodative in response to negative demand shocks when there is a risk of hitting the ZLB; see Adam and Billi (2007) and Nakov (2008). Fiscal stimulus with government spending in a liquidity trap has been shown to be more aggressive when the ZLB is occasionally binding; see Schmidt (2013) and Nakata (2016). This paper contributes to these studies by enriching the set of fiscal instruments. My analysis uncovers a novel policy incentive that affects government debt dynamics: it is optimal to trade off taxation smoothing, which

\footnotetext{
${ }^{4}$ Bhattarai et al. (2015) use long-term government debt to model quantitative easing in a liquidity trap as changing debt maturity while keeping debt level constant. The current paper abstracts from this unconventional monetary policy by keeping debt maturity constant.
} 
is a common goal in the optimal choice of distortionary taxes, against a relief of the deflationary effect created by expectations of hitting the ZLB.

The remainder of this paper is organized as follows. Section 2 describes the model and the policy problem. Section 3 uses a simplified version of the model to provide an analytical characterization of the effects of issuing debt in a liquidity trap. Section 4 studies optimal policy numerically after calibrating the model. Section 5 performs sensitivity analysis. Section 6 concludes.

\section{The Model}

The model described in this section is a standard New Keynesian business cycle model with monopolistic competition and costly price adjustment in the production sector. The model economy is populated by four types of agents: an infinitely lived representative household, a representative aggregate-good producer, intermediate-goods producers, and the government. Time is discrete and indexed by $t$.

\subsection{Households}

The representative household derives utility from private consumption of the aggregate good, $c_{t}$, and consumption of the aggregate public good, $G_{t}$, provided by the government. Labor, $h_{t}$, supplied by the household generates disutility. Expected lifetime utility of the household is defined by

$$
\mathbb{E}_{0} \sum_{t=0}^{\infty} \beta^{t} \xi_{t}\left[u\left(c_{t}\right)+g\left(G_{t}\right)-v\left(h_{t}\right)\right],
$$

where $\mathbb{E}_{t}$ is the rational expectations operator conditional on information in period $t, \beta \in(0,1)$ is the average time discount factor, and $\xi_{t}$ is the exogenous shock that affects time preference. Note that the rate of time preference between states in two consecutive periods is given by $\xi_{t} /\left(\beta \xi_{t+1}\right)$. The preference shock 
is assumed to follow the stationary process

$$
\log \left(d_{t}\right)=\varrho \log \left(d_{t-1}\right)+\varepsilon_{t}
$$

where $d_{t} \equiv \xi_{t+1} / \xi_{t}$ is the transformation of the preference shock that reflects changes in the rate of time preference (patience) of the household, $\varrho \in[0,1)$ is the persistence coefficient, and $\varepsilon_{t} \sim N\left(0, \sigma^{2}\right)$ is the i.i.d. innovation. The variable $d_{t}$ is referred to as the demand shock because it affects the consumptionsavings decision of the household. The functions $u$ and $g$ are assumed to be increasing and concave, whereas $v$ is assumed to be increasing and convex.

The flow budget constraint of the household takes the following form:

$$
P_{t} c_{t}+R_{t}^{-1} B_{t}^{s}+q_{t} B_{t}=\left(1-\tau_{t}\right) W_{t} h_{t}+B_{t-1}^{s}+\left(1+\rho q_{t}\right) B_{t-1}+\int_{0}^{1} \Pi_{i, t} d i-T_{t},
$$

where $P_{t}$ is the unit price of the aggregate consumption good, $W_{t}$ is the nominal wage, $\tau_{t}$ is the linear tax rate on labor income, $\Pi_{i, t}$ is the share of profits from sales of the intermediate good of type $i$ distributed in a lump-sum way, and $T_{t}$ is the lump-sum tax collected by the government. The household trades two types of nominal government bonds: (1) the one-period discount bonds, $B_{t}^{s}$, are sold at the price equal to the inverse of the one-period nominal risk-free interest rate, $R_{t}$, and (2) the perpetual (long-term) bonds, $B_{t}$, with the structure of payoffs decaying at the exponential rate $\rho \in[0,1]$ as in Woodford (2001), are sold at the price $q_{t}$.

The household maximizes expected lifetime utility (2.1) by choosing a plan for private consumption, labor, and bond holdings $\left\{c_{t}, h_{t}, B_{t}^{S}, B_{t}\right\}_{t=0}^{\infty}$ subject to the sequence of flow budget constraints (2.3) and an implicitly assumed no-Ponzi condition. The optimal plan of the household has to satisfy (2.3) and a transversality condition, as well as the following first-order conditions: 


$$
\begin{aligned}
\frac{v^{\prime}\left(h_{t}\right)}{u^{\prime}\left(c_{t}\right)} & =\left(1-\tau_{t}\right) w_{t}, \\
u^{\prime}\left(c_{t}\right) & =\beta d_{t} R_{t} \mathbb{E}_{t}\left\{\frac{u^{\prime}\left(c_{t+1}\right)}{\pi_{t+1}}\right\}, \\
u^{\prime}\left(c_{t}\right) & =\frac{\beta d_{t}}{q_{t}} \mathbb{E}_{t}\left\{\frac{\left(1+\rho q_{t+1}\right) u^{\prime}\left(c_{t+1}\right)}{\pi_{t+1}}\right\},
\end{aligned}
$$

where $\pi_{t+1} \equiv P_{t+1} / P_{t}$ is the gross one-period inflation rate, and $w_{t} \equiv W_{t} / P_{t}$ is the real wage.

\section{$2.2 \quad$ Firms}

The aggregate consumption good, $y_{t}$, is produced by the perfectly competitive firms that use the constant-returns-to-scale technology,

$$
y_{t}=\left(\int_{0}^{1} y_{i, t}^{\frac{\theta-1}{\theta}} d i\right)^{\frac{\theta}{\theta-1}}
$$

where $y_{i, t}$ is the production input of the intermediate good of type $i$, and $\theta>1$ is the elasticity of substitution across different types of the intermediate goods indexed by $i \in[0,1]$. The profit-maximizing producer of the aggregate good demands every intermediate good, $i$, in accordance with the following demand function:

$$
y_{i, t}=\left(\frac{P_{i, t}}{P_{t}}\right)^{-\theta} y_{t},
$$

where $P_{i, t}$ is the price of the intermediate good $i$, and the aggregate price level $P_{t}$ can be written as the index of the intermediate goods prices $P_{t}=$ $\left(\int_{0}^{1} P_{i, t}^{1-\theta} d i\right)^{\frac{1}{1-\theta}}$.

Every intermediate good, $y_{i, t}$, is produced with the linear technology,

$$
y_{i, t}=h_{i, t}
$$

where $h_{i, t}$ is the input of labor hired by the firm. The firms that produce the 
intermediate goods compete monopolistically and face a quadratic cost of price adjustment. Given demand for each intermediate good, each of these firms chooses price, $P_{i, t}$, of the good so as to maximize a present discounted real value of profits,

$$
\mathbb{E}_{0} \sum_{t=0}^{\infty} \beta^{t} \xi_{t} \frac{u^{\prime}\left(c_{t}\right)}{P_{t}}\left[P_{i, t} y_{i, t}-(1-s) W_{t} y_{i, t}-\frac{\varphi}{2}\left(\frac{P_{i, t}}{P_{i, t-1}}-1\right)^{2} P_{t} y_{t}\right]
$$

where $s$ is the time-invariant rate of a labor (employment) subsidy provided by the government to eliminate steady-state distortions created by monopolistic competition and taxation of labor income, and $\varphi \geqslant 0$ measures the degree of nominal price rigidity introduced by the cost of price adjustment.

In equilibrium, all the firms that produce the intermediate goods behave symmetrically and charge identical prices $P_{i, t}=P_{t}$ for all $i \in[0,1]$. Then, the optimizing behavior of the intermediate-goods producers is characterized by the first-order condition of the pricing problem that can be written as

$$
(1-s) w_{t}-\frac{(\theta-1)}{\theta}=\frac{\varphi}{\theta}\left(\left(\pi_{t}-1\right) \pi_{t}-\beta d_{t} \mathbb{E}_{t}\left\{\frac{u_{c, t+1}}{u_{c, t}} \frac{y_{t+1}}{y_{t}}\left(\pi_{t+1}-1\right) \pi_{t+1}\right\}\right) .
$$

The symmetric pricing also implies that all these firms produce the same amount of output and hire the same amount of labor, hence $y_{i, t}=y_{t}$ and $h_{i, t}=h_{t}$ for all $i \in[0,1]$. Therefore, one can write the aggregate production function as

$$
y_{t}=h_{t},
$$

and the aggregate resource constraint resulting from the clearing of the goods market as

$$
h_{t}=c_{t}+G_{t}+\frac{\varphi}{2}\left(\pi_{t}-1\right)^{2} h_{t} .
$$




\subsection{The Government}

The government consists of a central bank and a treasury. The central bank controls the short-term nominal interest rate, $R_{t}$. Importantly, this monetary policy instrument is constrained by the ZLB,

$$
R_{t} \geqslant 1
$$

The treasury chooses the amount of spending on public good provision to the household, $G_{t}$. To finance government spending, the treasury levies labor income tax at the rate $\tau_{t}$ and participates in the bond market. Assuming that the one-period bonds are in zero net supply, the consolidated budget constraint of the government reads as

$$
q_{t} B_{t}=\left(1+\rho q_{t}\right) B_{t-1}+P_{t} G_{t}-\left(\tau_{t}-s\right) W_{t} h_{t}-T_{t} .
$$

The lump sum tax, $T_{t}$, is restricted to be used for the sole purpose of transferring resources corresponding to the employment subsidy. Furthermore, since the goal of subsidizing employment is to correct the steady-state distortions, the lump-sum tax is set to be constant over time and equal to the steady-state value of the subsidy. The flow budget constraint of the government in real terms is then given by

$$
q_{t} b_{t}=\left(1+\rho q_{t}\right) \frac{b_{t-1}}{\pi_{t}}+\left(G_{t}+\varsigma_{t}-\tau_{t} w_{t} h_{t}\right),
$$

where $b_{t} \equiv B_{t} / P_{t}$ is the quantity of the long-term government bonds in real terms, and $\varsigma_{t} \equiv s w_{t} h_{t}-s \bar{w} \bar{h}$ is the deviation of the subsidy from its steady-state level in real terms. Bars are used to denote steady-state values.

\subsection{Simplified Version of the Model}

This paper also considers a simplified version of the model where government spending is exogenous and constant over time, $G_{t}=\bar{G}$, the long-term government bonds are indexed to inflation, and the lump-sum tax finances the subsidy also outside of the steady state, $\varsigma_{t}=0$. In this case, the flow budget constraint 
of the government in real terms reads as

$$
q_{t} b_{t}=\left(1+\rho q_{t}\right) b_{t-1}+\left(\bar{G}-\tau_{t} w_{t} h_{t}\right)
$$

and the budget constraint of the representative household is adjusted accordingly so that the first-order condition (2.6) is replaced by

$$
u^{\prime}\left(c_{t}\right)=\frac{\beta d_{t}}{q_{t}} \mathbb{E}_{t}\left\{\left(1+\rho q_{t+1}\right) u^{\prime}\left(c_{t+1}\right)\right\}
$$

\subsection{The First-Best Allocation}

The first-best allocation is defined as the solution of a social planner problem. The planner eliminates monopoly power of the intermediate-goods producers and allocates resources efficiently across different types of the intermediate goods. The planner maximizes expected lifetime utility (2.1) of the household subject to the sequence of aggregate resource constraints of the following form:

$$
h_{t}=c_{t}+G_{t}
$$

Solution of this problem is described in Appendix A.1. The first-order conditions of the problem imply that the period marginal utility components of private and public consumption at the optimum are set equal to marginal disutility of labor:

$$
\begin{aligned}
& 0=g^{\prime}\left(G_{t}\right)-u^{\prime}\left(c_{t}\right), \\
& 0=g^{\prime}\left(G_{t}\right)-v^{\prime}\left(h_{t}\right) .
\end{aligned}
$$

The optimality conditions (2.14)-(2.16) are static. Thus, the first-best allocation $\left(c_{t}, h_{t}, G_{t}\right)$ is constant over time. It is optimal to allocate a fixed amount of labor to production of output and then allocate fixed shares of output to private and public consumption. The first-best allocation serves as a benchmark for a private-sector equilibrium under optimal government policy described below. 


\subsection{Private-Sector Equilibria and the Policy Problem}

Given an exogenous process for the demand shock, $d_{t}$, and initial outstanding government debt, $b_{-1}$, the private-sector equilibrium is a sequence of stochastic processes $\left\{c_{t}, y_{t}, h_{t}, \pi_{t}, w_{t}, q_{t}, b_{t}, G_{t}, \tau_{t}, R_{t}\right\}_{t=0}^{\infty}$ such that: (1) $\left\{c_{t}, h_{t}, b_{t}\right\}_{t=0}^{\infty}$ solve the problem of the household given prices and policies, (2) $\left\{\pi_{t}\right\}_{t=0}^{\infty}$ conforms to the optimal pricing behavior of the firms, (3) the government budget constraint and the ZLB on the nominal interest rate are satisfied, and (4) the markets for goods and labor are clear. The private-sector equilibrium has to satisfy equations (2.4)-(2.11).

This paper studies private-sector equilibria that solve a policy problem of the government. The government acts benevolently with the objective of maximizing expected lifetime utility (2.1) of the household. The government credibly commits to repay its debt but lacks commitment to any future path of the policy instruments. In every period, the government chooses the contemporaneous policy instruments as a function of payoff-relevant state variables: the demand shock realization and outstanding debt. The government takes into account how its current choice of government debt affects future choices. Formally, optimal policy is a part of the Markov-Perfect equilibrium, which is associated with a solution to the following Bellman equation:

$$
\mathcal{V}\left(s_{t}\right)=\max _{\delta_{t}}\left[u\left(c_{t}\right)+g\left(G_{t}\right)-v\left(h_{t}\right)\right]+\beta d_{t} \mathbb{E}_{t}\left\{\mathcal{V}\left(s_{t+1}\right)\right\}
$$

subject to

$$
\begin{aligned}
0 & =\Upsilon\left(s_{t}, \delta_{t}, \mathcal{C}\left(s_{t+1}\right), \mathcal{Y}\left(s_{t+1}\right), \Pi\left(s_{t+1}\right), \mathcal{Q}\left(s_{t+1}\right)\right), \\
R_{t} & \geqslant 1,
\end{aligned}
$$

where $s_{t} \equiv\left(b_{t-1}, d_{t}\right)$ is the vector of states; $\delta_{t} \equiv\left(c_{t}, y_{t}, h_{t}, \pi_{t}, w_{t}, q_{t}, b_{t}, G_{t}, \tau_{t}, R_{t}\right)$ is the vector of choices; $\Upsilon$ is the vector-function that summarizes private-sector equilibrium conditions (2.4)-(2.9), (2.11); and $(\mathcal{C}, \mathcal{Y}, \mathcal{H}, \Pi, \mathcal{W}, \mathcal{Q}, \mathcal{B}, \mathcal{G}, \mathcal{T}, \mathcal{R})$ are the decision rules that generate the private-sector equilibrium, as in $c_{t}=$ $\mathcal{C}\left(s_{t}\right), y_{t}=\mathcal{Y}\left(s_{t}\right)$, etc., which solves this dynamic problem. 
Without uncertainty, the Markov-Perfect equilibrium features an efficient steady state, that is, the steady state consistent with the first-best allocation; see Appendix A.2. One can solve for the efficient steady state independently of optimal dynamic policy. In this deterministic steady state inflation is zero and the level of government debt depends on the rate of employment subsidy. In what follows, the subsidy rate is assumed to be such that the efficient deterministic steady state is supported by a positive amount of government debt. ${ }^{5}$

Also, for the remainder of the paper it is assumed that utility derived by the households from private consumption and consumption of public goods is described by $u\left(c_{t}\right) \equiv c_{t}^{\left(1-\gamma_{c}\right)} /\left(1-\gamma_{c}\right)$ and $g\left(G_{t}\right) \equiv \nu_{g} G_{t}^{\left(1-\gamma_{g}\right)} /\left(1-\gamma_{g}\right)$, and disutility from work is described by $v\left(h_{t}\right) \equiv \nu_{h} h_{t}^{\left(1+\gamma_{h}\right)} /\left(1+\gamma_{h}\right)$.

\section{Example with One-period Liquidity Trap}

This section provides analytical characterization of the effects of government debt in the liquidity trap using a simplified version of the model where government spending is assumed to be equal to the constant first-best level and debt is indexed to inflation. The characterization is derived using a linear-quadratic approximation of the policy problem around the efficient deterministic steady state. ${ }^{6}$ The objective function of the government is approximated up to the second order. The private-sector equilibrium conditions, except for the ZLB, are approximated linearly.

\subsection{The Linear-Quadratic Policy Problem}

The approximated Markov-Perfect equilibrium consists of a value function, $\mathcal{U}$, and decision rules $(\hat{\mathcal{Y}}, \hat{\Pi}, \hat{\mathcal{Q}}, \hat{\mathcal{B}}, \hat{\mathcal{T}}, \hat{\mathcal{I}})$. The value function and each decision

\footnotetext{
${ }^{5} \mathrm{~A}$ similar assumption is made, e.g., in Burgert and Schmidt (2014) and Leith and Wren-Lewis (2013).

${ }^{6}$ The simplified version of the model features the efficient deterministic steady state identical to the efficient deterministic steady state of the model with nominal government debt and endogenously chosen government spending.
} 
rule are a function of $\hat{b}_{t-1}$ and $\hat{d}_{t}$, such that for any $\hat{b}_{t-1}$ and $\hat{d}_{t}$, the quantities, prices, and policies generated by these rules $\left(\hat{y}_{t}=\hat{\mathcal{Y}}\left(\hat{b}_{t-1}, \hat{d}_{t}\right), \hat{\pi}_{t}=\right.$ $\left.\hat{\Pi}\left(\hat{b}_{t-1}, \hat{d}_{t}\right), \ldots, \hat{i}_{t}=\hat{\mathcal{I}}\left(\hat{b}_{t-1}, \hat{d}_{t}\right)\right)$ solve the following problem:

$$
\mathcal{U}\left(\hat{b}_{t-1}, \hat{d}_{t}\right)=\max _{\left(\hat{y}_{t}, \hat{\pi}_{t}, \hat{q}_{t}, \hat{b}_{t}, \hat{t}_{t}, \hat{i}_{t}\right)}\left\{-\frac{1}{2}\left(\vartheta \hat{y}_{t}^{2}+\hat{\pi}_{t}^{2}\right)+\beta \mathbb{E}_{t} \mathcal{U}\left(\hat{b}_{t}, \hat{d}_{t+1}\right)\right\}
$$

subject to

$$
\begin{aligned}
\hat{\pi}_{t} & =\beta \mathbb{E}_{t} \hat{\pi}_{t+1}+\kappa \hat{y}_{t}+\lambda \hat{\tau}_{t} \\
\hat{y}_{t} & =-\tilde{\gamma}_{c}^{-1}\left(\hat{i}_{t}-\mathbb{E}_{t} \hat{\pi}_{t+1}\right)+\mathbb{E}_{t} \hat{y}_{t+1}-\tilde{\gamma}_{c}^{-1} \hat{d}_{t}, \\
\bar{\Gamma} \hat{b}_{t} & =\beta^{-1} \bar{\Gamma} \hat{b}_{t-1}-(1-\rho) \bar{\Gamma} \hat{q}_{t}-\bar{\tau} \bar{w} \bar{y}\left((1+\bar{\tau} \bar{w}) \hat{\tau}_{t}+\left(1+\tilde{\gamma}_{c}+\gamma_{h}\right) \hat{y}_{t}\right), \\
\hat{i}_{t} & =\left(\rho \beta \mathbb{E}_{t} \hat{q}_{t+1}-\hat{q}_{t}\right)+\mathbb{E}_{t} \hat{\pi}_{t+1} \\
\hat{i}_{t} & \geqslant-r^{*}
\end{aligned}
$$

where a bar denotes the deterministic steady-state value, and a hat denotes the percentage deviation from the deterministic steady state. Additionally, $\bar{\Gamma} \equiv \bar{b} \bar{q}$ is the market value of government debt in the deterministic steady state, and $\hat{i}_{t}$ is the percentage deviation of the short-term nominal interest rate $R_{t}$. Composite parameter $\tilde{\gamma}_{c} \equiv \gamma_{c}(\bar{y} / \bar{c})$ is the elasticity of marginal utility of private consumption with respect to total output evaluated in the steady state, and $r^{*} \equiv \log (1 / \beta)$ is the net real interest rate in the steady state. Remaining composite parameters $\lambda, \kappa, \vartheta>0$ are given by

$$
\kappa \equiv \frac{(\theta-1)}{\varphi}\left(\tilde{\gamma}_{c}+\gamma_{h}\right), \quad \lambda \equiv \frac{(\theta-1)}{\varphi} \bar{\tau} \bar{w}, \quad \vartheta \equiv \frac{\kappa}{(\theta-1)}
$$

Derivation of the quadratic objective function (3.1) is described in Appendix A.4. Equation (3.2) is a Phillips curve derived from a log-linear version of equation (2.7). The dynamic investment-savings equation (3.3) is derived from a log-linear version of equation (2.5). Equation (3.4) is derived from a log-linearized flow budget constraint of the government (2.12). When deriving these equations, log-linear versions of equations (2.4), (2.9), and (2.8) are used 
to simplify the problem by substituting for and eliminating the real wage, $\hat{w}_{t}$; private consumption, $\hat{c}_{t}$; and employment, $\hat{h}_{t}$. Equation (3.5) is a no-arbitrage condition between the price of government bonds and the nominal interest rate derived using log-linear versions of equations (2.5) and (2.13). Inequality (3.6) captures the ZLB constraint.

When solving the problem, the government takes into account that the current choice of government bonds passed over into the next period, $\hat{b}_{t}$, affects optimal choice in the next period. In particular, next-period output, inflation, and the price of government bonds are determined by the corresponding equilibrium decision rules $\hat{y}_{t+1}=\hat{\mathcal{Y}}\left(\hat{b}_{t}, \hat{d}_{t+1}\right), \hat{\pi}_{t+1}=\hat{\Pi}\left(\hat{b}_{t}, \hat{d}_{t+1}\right)$, and $\hat{q}_{t+1}=$ $\hat{\mathcal{Q}}\left(\hat{b}_{t}, \hat{d}_{t+1}\right)$. The set of optimality conditions for the linear-quadratic policy problem consists of

$$
\begin{aligned}
\hat{y}_{t} & =\Phi_{y} \hat{\pi}_{t}+\left(\tilde{\gamma}_{c} / \vartheta\right) \alpha_{t}, \\
\hat{\pi}_{t} & =\mathbb{E}_{t} \hat{\pi}_{t+1}+\Phi_{\pi, t} \hat{\pi}_{t}+\mu \Phi_{\alpha, t} \alpha_{t}, \\
0 & =\alpha_{t}\left(\hat{i}_{t}+r^{*}\right), \\
0 & \geqslant \alpha_{t},
\end{aligned}
$$

as well as conditions (3.2)-(3.6), where

$$
\begin{aligned}
\mu & \equiv\left[\frac{\bar{y}(1+\bar{\tau} \bar{w})\left(\tilde{\gamma}_{c}+\gamma_{h}\right)}{\kappa \bar{\Gamma}}\right], \\
\Phi_{y} & \equiv\left[-1+\frac{1+1 /\left(\tilde{\gamma}_{c}+\gamma_{h}\right)}{1+1 / \bar{\tau} \bar{w}}+\frac{(1-\rho) \tilde{\gamma}_{c}}{\mu \kappa}\right][\theta-1], \\
\Phi_{\pi, t} & \equiv\left[\mu \beta \frac{\mathbf{d} \mathbb{E}_{t} \hat{\pi}_{t+1}}{\mathbf{d} b_{t}}+(1-\rho)\left(\tilde{\gamma}_{c} \frac{\mathbf{d} \mathbb{E}_{t} \hat{y}_{t+1}}{\mathbf{d} b_{t}}-\rho \beta \frac{\mathbf{d} \mathbb{E}_{t} \hat{q}_{t+1}}{\mathbf{d} b_{t}}\right)\right], \\
\Phi_{\alpha, t} & \equiv\left[\frac{\mathbf{d} \mathbb{E}_{t} \hat{\pi}_{t+1}}{\mathbf{d} b_{t}}+\tilde{\gamma}_{c} \frac{\mathbf{d} \mathbb{E}_{t} \hat{y}_{t+1}}{\mathbf{d} b_{t}}\right] .
\end{aligned}
$$

Variable $\alpha_{t}$ is the Lagrange multiplier associated with the ZLB constraint (3.6).

The optimality conditions (3.2)-(3.10) show that the presence of the ZLB and the lack of lump-sum taxes make it a nontrivial problem to stabilize the economy subject to demand shocks. First, a binding ZLB in itself, which 
implies $\alpha_{t}<0$, makes the bliss point $\hat{\pi}_{t}=\hat{y}_{t}=0$ unattainable as can be seen from the targeting rule (3.7). Second, a mere risk of reaching the ZLB works its way through the expectation term in the Phillips curve (3.2) and prevents the full stabilization outcome. Third, even when abstracting from the ZLB, a need to adjust the distortionary tax to keep the government budget constraint satisfied has a by-product of cost-push effect in the Phillips curve (3.2), which creates a trade-off between inflation and output. ${ }^{7}$

\subsection{Government Debt in the Liquidity Trap}

The remainder of this section abstracts from the risk of reaching the ZLB. The focus of analysis below is on the effects and the choice of government debt when the ZLB is actually binding. The choice of government debt in the liquidity trap affects dynamics of the economy in the subsequent periods, which feeds back into and affects the economic outcome in the liquidity trap through expectations. In other words, the government can improve stabilization of inflation and output in the liquidity trap by adjusting the amount of government debt it issues in this very period.

To keep the analysis simple, the liquidity trap is assumed to last for one period. In period 0 the economy is hit by a strong enough negative demand shock, $\hat{d}_{0} \gg 0$, to make the ZLB binding, $\alpha_{0}<0$. In the next period, demand reverts to its steady state and all uncertainty is resolved forever: $\hat{d}_{t}=0$ for all $t \geqslant 1$. The optimal level of government debt at the end of period 0 is assumed to be such that the ZLB is not binding in period $1 .^{8}$ Moreover, the analysis is restricted to equilibria that exhibit monotone dynamics after the lift-off of the nominal interest rate from the lower bound in period 1 . Then, the decision rules for $t \geqslant 1$ are linear functions of outstanding government debt $\left(\hat{y}_{t}=\mathcal{Y}_{b} \hat{b}_{t-1}, \hat{\pi}_{t+1}=\Pi_{b} \hat{b}_{t-1}, \ldots, \hat{i}_{t}=\mathcal{I}_{b} \hat{b}_{t-1}\right)$. Finally, increasing issuance of government debt in the liquidity trap is assumed to lead to higher inflation

\footnotetext{
${ }^{7}$ There is a so-called "divine coincidence" of full stabilization of inflation and output, $\hat{\pi}_{t}=\hat{y}_{t}=0$, only when outstanding government debt is in the form of consol bonds, $\rho=1$, and is equal to the steady-state level, $\hat{b}_{t-1}=0$.

${ }^{8}$ This assumption is without loss of generality: the analysis can be immediately generalized by assuming that period 0 is the last period when the ZLB is binding.
} 
when the nominal interest rate is positive, i.e., $\Pi_{b}>0 .^{9}$

First, consider the effect of varying government debt choice on output in period 0 when the economy is assumed to be guided by optimal policy starting from period 1. To do this, one can solve the dynamic investment-savings equation (3.3) forward to get the following expression:

$$
\begin{aligned}
\hat{y}_{0}=-\tilde{\gamma}_{c}^{-1} \underbrace{\left(-r^{*}-\hat{\pi}_{1}\right)}_{\text {current real rate }}-\tilde{\gamma}_{c}^{-1} \underbrace{\sum_{i=1}^{\infty}\left(\hat{i}_{t+i}-\hat{\pi}_{t+i+1}\right)}_{\text {expected real rates }}-\tilde{\gamma}_{c}^{-1} \hat{d}_{0} \\
=-\tilde{\gamma}_{c}^{-1} \underbrace{\left(-r^{*}-\Pi_{b} \hat{b}_{0}\right)}_{\text {current real rate }}-\tilde{\gamma}_{c}^{-1} \underbrace{\left(-\tilde{\gamma}_{c} \Phi_{y} \Pi_{b} \hat{b}_{0}\right)}_{\text {expected real rates }}-\tilde{\gamma}_{c}^{-1} \hat{d}_{0},
\end{aligned}
$$

where one uses the simplifying assumptions laid out above and the second equality follows from imposing optimality conditions (3.7) and (3.8) from period 1 onward. The previous expression shows that output in the liquidity trap, $\hat{y}_{0}$, is proportional to current and expected real interest rates. The real interest rates are, in turn, pinned down by the choice of government debt in the liquidity trap, $\hat{b}_{0}$. The following proposition characterizes the link between the choice of government debt and output in the liquidity trap.

Proposition 1. The effect of varying government debt choice on output in the liquidity trap depends on the value of coefficient $\Phi_{y}$ :

1. If $\Phi_{y}>0$ or $-\tilde{\gamma}_{c}^{-1}<\Phi_{y}<0$, larger debt stimulates output: $\frac{d \hat{y}_{0}}{d \hat{b}_{0}}>0$,

2. If $\Phi_{y}<-\tilde{\gamma}_{c}^{-1}<0$, larger debt contracts output: $\frac{d \hat{y}_{0}}{d \hat{b}_{0}}<0$.

The proof follows from equation (3.15). The comparative difference described in Proposition 1 stems from the change in the effect of varying government debt choice on expected real interest rates. While current real interest rate is unambiguously lower the larger is government debt, expected real interest rates are lower the larger is government debt only if $\Phi_{y}>0$. Larger government

\footnotetext{
${ }^{9}$ This assumption is not restrictive as it holds when an increase of government debt makes the government budget constraint tighter under positive nominal interest rate.
} 
debt, therefore, leads to lower output when stimulus from lower current real interest rate is more than offset by the contractionary effect of higher expected real interest rates, i.e., when $\Phi_{y}<-\tilde{\gamma}_{c}^{-1}<0$.

Second, consider how the comparative difference described in Proposition 1 is manifested in the optimal choice of government debt in the liquidity trap. One can do that by rewriting the optimality condition (3.8) that describes the optimal way to balance the intertemporal trade-off faced by the government in period 0 as follows:

$$
\hat{\pi}_{0}=\Pi_{b} \hat{b}_{0}+\Phi_{\pi} \hat{\pi}_{0}+\alpha_{0} \Pi_{b}\left(1+\tilde{\gamma}_{c} \Phi_{y}\right) \mu
$$

where, given the simplifying assumptions laid out above, $\Phi_{\pi} \in(0,1)$ and is defined as follows:

$$
\Phi_{\pi} \equiv\left[\mu \beta \Pi_{b}+(1-\rho)\left(\tilde{\gamma}_{c} \mathcal{Y}_{b}-\rho \beta \mathcal{Q}_{b}\right)\right] .
$$

Equation (3.16) implicitly determines the optimal choice of government debt in the liquidity trap by equalizing marginal benefits and marginal costs of government debt. The last term on the right-hand side is specific to the liquidity trap and turns out to be the component of either costs or benefits depending on the effect of changing government debt on output.

Proposition 2. The marginal desirability of government debt in the liquidity trap depends on the value of coefficient $\Phi_{y}$ :

1. If $\Phi_{y}>0$ or $-\tilde{\gamma}_{c}^{-1}<\Phi_{y}<0$, a marginal increase of $\hat{b}_{0}$ provides additional benefit in the liquidity trap: $\alpha_{0} \Pi_{b}\left(1+\tilde{\gamma}_{c} \Phi_{y}\right) \mu<0$,

2. If $\Phi_{y}<-\tilde{\gamma}_{c}^{-1}<0$, a marginal increase of $\hat{b}_{0}$ creates additional cost in the liquidity trap: $\alpha_{0} \Pi_{b}\left(1+\tilde{\gamma}_{c} \Phi_{y}\right) \mu>0$.

The proof follows from equation (3.16). In the case when larger debt stimulates output, issuing the marginal unit of debt provides benefit as it mitigates deflation in the liquidity trap. In the case when larger debt has a contractionary 
effect on output, issuing the marginal unit of debt only exacerbates deflation and is therefore costly.

Next, consider the reason for coefficient $\Phi_{y}$ shaping the effects and the choice of government debt in the liquidity trap. Recall that the sign of coefficient $\Phi_{y}$ changes the reaction of expected real interest rates to government debt. The underlying reason is that $\Phi_{y}$ implicitly characterizes the stance of monetary policy from period 1 onward. One can see that by writing the optimal choice of the nominal interest rate for $t \geq 1$ as a feedback to expected inflation,

$$
\hat{i}_{t}=\gamma_{\pi} \hat{\pi}_{t+1}
$$

where the feedback coefficient on expected inflation is defined as follows:

$$
\gamma_{\pi} \equiv\left(1-\tilde{\gamma}_{c} \Phi_{y} \frac{\Phi_{\pi}}{\left(1-\Phi_{\pi}\right)}\right)
$$

The expression above shows that the nominal interest rate reacts more (less) than one-to-one to expected inflation if $\Phi_{y}<(>) 0$.

An important determinant of the stance of monetary policy when the nominal interest rate is away from the lower bound is the average maturity of government debt. Using (3.12) one can see that $\Phi_{y}$ is a decreasing function of the maturity parametrized by $\rho$. The longer is the maturity the weaker is the incentive to set monetary policy to mitigate the need of changing the tax rate relative to the incentive to mitigate the inflationary effect of changing the tax rate. This result is extensively discussed in Matveev (2016). The quantitative analysis in that paper also finds that $\Phi_{y}$ is negative in the economy with long-term debt and positive in the economy with short-term debt.

Finally, note that the analysis above does not characterize the optimal choice of government debt explicitly. In similar models with one-period debt, Eggertsson (2006) and Burgert and Schmidt (2014) have shown that the government should increase debt in a liquidity trap. The former argued that an increase in debt is optimal as larger debt stimulates the economy by raising expected inflation, which reduces current real interest rate in a 
liquidity trap. The latter found that larger debt also reduces expected real interest rates, thereby reinforcing economic stimulus. The analysis in the current section shows that larger debt may raise expected real interest rates and be contractionary if the maturity is long enough. One can thus expect government debt reduction to be a potentially desirable response in a liquidity trap with long-term debt - a conjecture confirmed in the next section. ${ }^{10}$

\section{Quantitative Exercise}

This section studies a calibrated version of the model numerically. Compared with the previous section, the analysis here relaxes the assumptions of constant government spending and indexation of government debt to inflation. Moreover, the demand shock follows the autoregressive process (2.2). Thus, the ZLB can be binding for multiple periods, and even when the nominal interest rate is positive there is a risk of reaching the bound in the future.

\subsection{Calibration and Solution}

The parameter values used for simulating the model are summarized in Table 1. Each time period in the model represents one quarter of a year. The utility weights, $\nu_{h}$ and $\nu_{g}$, are set to imply that in the efficient deterministic steady state households spend one quarter of their unitary time endowment working and government spending amounts to 20 percent of output. The time discount factor, $\beta$, is set to match the annual real interest rate of 2.5 percent in the efficient deterministic steady state. The parameters of the demand shock process are chosen to be consistent with the values in Burgert and Schmidt (2014) that are based on US data for 1983-2010.

The elasticity of substitution between the intermediate goods, $\theta$, is set to match the desired markup of the price over the marginal cost of 10 percent.

\footnotetext{
${ }^{10}$ In models with one-period debt and commitment to policy choices, Eggertsson and Woodford (2006) and Nakata (2017) have shown that debt is reduced in a liquidity trap under optimal policy. The effects focused on in the current paper are specific to the environment without commitment, where debt is used to strategically affect future policy choices.
} 
Given the value of $\theta$, the parameter of price adjustment cost, $\varphi$, is set to match the slope of the Phillips curve consistent, up to the first order of approximation around the efficient deterministic steady state, with a Calvo (1983) price-setting specification where the average price duration is equal to one year.

With respect to the government debt characteristics, the model is calibrated as follows. The target for the market value of government debt in the efficient deterministic steady state is equal to 40 percent of annual GDP. This target is consistent with the pre-crisis US data available from the Federal Reserve Bank of Dallas. The parameter $\rho$ is set to match the average maturity of government debt equal to four years. This target is consistent with the pre-crisis duration of government debt in the US as reported in Greenwood et al. (2014).

Table 1 - Parameter Values

\begin{tabular}{lll}
\hline Parameter & Description & Value \\
\hline$\gamma_{c}$ & Intertemporal elasticity for $C$ & 1 \\
$\gamma_{g}$ & Intertemporal elasticity for $G$ & 1 \\
$\gamma_{h}$ & Inverse Frisch elasticity & 1 \\
$\nu_{g}$ & Utility weight on gov't spending & 0.25 \\
$\nu_{h}$ & Utility weight on labor & 20 \\
$\beta$ & Time discount factor & 0.99385 \\
$\varrho$ & AR coefficient demand shock & 0.77 \\
$\sigma$ & S.D. demand shock innovation (\%) & 0.40 \\
$\varphi$ & Price adjustment cost & 116.505 \\
$\theta$ & Elasticity of substitution among goods & 11 \\
$\rho$ & Bonds payoff decay factor & 0.9433 \\
\hline
\end{tabular}

The model is solved using a global nonlinear approximation method; see Appendix A.5 for details. There are two types of nonlinearity in the model: first, a nonlinearity in the equality conditions of the private-sector equilibrium; and second, a nonlinearity imposed by the ZLB. The exercise below starts by describing optimal policy when the ZLB is abstracted from and then moves to the case that takes it into account. 


\subsection{Demand Stabilization without the ZLB}

As was discussed in Section 3, complete stabilization of the economy subject to demand shocks is not possible even in the case when monetary policy is not constrained by the ZLB. The analysis here looks at the quantitative effects of a demand shock in such a case. It is assumed that government debt is stabilized before the shock hit. More precisely, prior to the shock the economy is assumed to reside in the risky steady state: a point where the economy converges to conditional on the demand shock staying at the unconditional average (see Coeurdacier et al. (2011)). Without the ZLB, the market value of government debt relative to the annual GDP at the risky steady state is 2 percentage points higher compared with the deterministic steady state. See Table 2 for a detailed comparison of deterministic and risky steady states.

Figure 1 shows an impulse response to the negative demand shock of three unconditional standard deviations. The displayed response shows conditional dynamics in the absence of any shocks in the future. The dynamics of consumption, output and government spending are reported in terms of percentage deviations from the risky steady state. Inflation, the nominal and the real interest rates, as well as the rate of time preference (dashed blue line), are reported in annualized percentages. The labor tax rate is reported as a percentage-point difference from the risky steady state. The dynamics of government debt are reported in terms of percentage-point difference between the end-of-period market value of government debt as a share of annualized output in the risky steady state and the respective ratio in the risky steady state.

[Figure 1 about here.]

The shock drives the rate of time preference into negative territory. The household becomes relatively more patient and is willing to postpone consumption. A decrease in the nominal interest rate offsets the effect of the shock on private demand. From the graph one can see that in the absence of the ZLB the nominal interest rate tracks the rate of time preference. In a standard New Keynesian model that assumes lump-sum taxes, such a monetary policy would completely stabilize the economy. Differently, in the current model 
with distortionary tax, a reduction of the nominal interest rate pushes up the price of government bonds. As the graph shows, it is then optimal to reduce the tax rate and increase government spending. The increase in government spending pushes aggregate demand up. This contributes to the increase in output. The reduction of the tax rate has a negative effect on the marginal cost of production, which pushes inflation down and output up. Government debt declines in response to the shock. The response of government debt is hump-shaped and the economy eventually settles on a gradual path of returning to the risky steady state.

The market value of government debt measured as a fraction of the annual risky steady-state level of output falls by 0.6 percentage points at its trough. The peaks of output and consumption responses are reached on impact and are less than 0.02 percent of the corresponding risky steady-state levels. The highest rate of the price level decline is less than 0.001 percent on impact. Overall, although there is no full stabilization, these results show that the economy does not experience strong fluctuations. It becomes especially clear when comparing the described response with the case where the ZLB is taken into account, which is analyzed in the remainder of this section.

\subsection{The Risk of a Liquidity Trap}

Taking the ZLB into account changes the equilibrium both when the ZLB is binding and when the policy rate is away from the bound. An instance of the latter type of changes described here first is a change of the risky steady state. The additional nonlinearity introduced by the ZLB drives the risky steady state further away from the deterministic counterpart.

Table 2 shows how the risk of a binding ZLB changes the steady state. The key change is in the amount of government debt. It increases and reaches 53 percent of annual GDP when valued at the market price. A convenient way to describe the mechanism behind the increase of government debt in the risky steady state is by looking at the equilibrium decision rules. 
Table 2 - Steady States

\begin{tabular}{llll}
\hline \multirow{2}{*}{ Variable } & Deterministic & \multicolumn{2}{c}{ Risky } \\
\cline { 2 - 4 } & & no ZLB & ZLB \\
\hline Output gap & 0 & -0.01 & -0.11 \\
Inflation & 0 & 0.004 & 0.045 \\
Nominal interest rate & 2.50 & 2.51 & 2.25 \\
Market value of debt & 40 & 42 & 53 \\
Labor tax rate & 17.35 & 17.37 & 17.54 \\
Government spending & 20 & 20 & 20 \\
\hline
\end{tabular}

Notes: Output gap is a relative difference from the deterministic steady state. Inflation and the nominal interest rate are in annual percentages. Market value of debt is in percentages relative to annual output. Spending is in percentages relative to output.

Figure 2 plots selected conditional decision rules as functions of the demand shock. The solid black lines represent decision rules conditional on the initial level of debt being equal to the risky steady-state value. The very left point of these decision rules corresponds to the risky steady state. The dashed blue lines represent decision rules conditional on the initial level of debt being equal to the deterministic steady-state value. Output is reported as a percentage deviation from the deterministic steady-state value. Inflation and the nominal interest rate are reported in annualized percentages. The labor tax rate is reported as a deviation from the deterministic steady-state value in percentage points.

[Figure 2 about here.]

Consider the case when the economy starts off with the level of government debt equal to the deterministic steady-state value. The graphs show that if the demand shock is large enough, then the ZLB becomes binding. The nominal interest rate fails to offset the fall of private demand. As a result, output and inflation decline. If the demand shock is equal to the unconditional average, then the expectations of reaching a state with a binding ZLB in the future reduce inflation today. Optimal response of monetary policy is to mitigate this deflationary effect by stimulating output with a lower nominal interest rate. 
Such a response affects the budget constraint of the government by raising the price of government bonds and the tax base. If the government were to maintain the initial level of government debt it would have to decrease the tax rate. This, however, would reinforce the deflationary pressure by driving the real marginal cost of production down.

The deflationary effect of the risk of a binding ZLB described above makes it optimal for the government to increase debt above the deterministic steadystate value. This debt increase mitigates the fall of prices today because of an associated increase of inflation expectations. Inflation expectations increase with government debt for two reasons. First, the tax rate is expected to go up and increase the marginal cost of production. Second, the probability of reaching the ZLB decreases because monetary policy is expected to become tighter. Importantly, increasing government debt until it reaches the risky steady state does not eliminate the states where the ZLB is binding.

The significance of changes in the risky steady state should be assessed against the magnitude of risk causing it. A convenient measure of the underlying risk is the unconditional probability of being at the ZLB in the equilibrium. Using a long sample simulated from the model to compute this measure resulted in the ZLB being binding 28 percent of the time. ${ }^{11}$ Such probability is high but within the range of recent estimates in Kiley and Roberts (2017). The sensitivity analysis performed below will consider a case with a lower risk of reaching the ZLB.

Finally, note that the average values of equilibrium variables are in general going to be different from the corresponding risky steady-state values. These differences are largely determined not only by the probability of being in a liquidity trap but also by the extent of economic stabilization in a liquidity trap. The remainder of this section focuses on the dynamic responses of the economy that has reached a state with a binding ZLB.

\footnotetext{
${ }^{11}$ The model is simulated for 100,000 periods starting from the risky steady state and then the first 5,000 observations are dropped so as to remove the influence of initial conditions.
} 


\subsection{The Response in a Liquidity Trap}

Consider the economy that has converged to the risky steady state. Figure 3 shows an impulse response of this economy when it is hit by the negative demand shock of three unconditional standard deviations. As in the case where the ZLB was abstracted from, the displayed response shows conditional dynamics in the absence of any shocks in the future and all the variables have the same units. Differently this time, the binding ZLB constrains the extent of stabilization and the economy experiences a stronger fluctuation. As output and inflation start to decline, the government uses fiscal policy to stabilize the economy.

[Figure 3 about here.]

The optimal response of fiscal policy features an increase in government spending in the impact period. The initial government spending expansion dies out until reaching the risky steady-state level. Higher government spending cushions a decline of aggregate demand due to the fall of private demand. When measured in terms of the risky steady-state output, the peak increase in government spending is equal to 0.5 percent. The resulting higher aggregate demand mitigates the decline of inflation. It is also optimal to temporarily raise the tax rate, then set it below and gradually increase it back to the risky steady-state rate. Increasing the labor tax rate when the ZLB starts binding is optimal because of the corresponding supply-side effect on prices. A higher tax rate pushes the marginal cost of production up and mitigates the decline of inflation. Qualitatively, responses of increasing tax rate and/or government spending are consistent with earlier findings in Eggertsson and Woodford (2006), Werning (2011), Schmidt (2013) and Nakata (2017), among others.

The focus of the current paper is on dynamics of government debt in a liquidity trap. The response of government debt is hump-shaped starting with a decline throughout the period of a binding ZLB and followed by a reversal after the nominal interest rate lifts off from the ZLB. ${ }^{12}$ The decline

\footnotetext{
${ }^{12}$ The decline of government debt amid the increase of government spending echoes the
} 
of government debt improves stabilization of output when the ZLB is binding because it stimulates private demand by lowering expected real interest rates. The expected real rates decline when government debt is reduced because the tax rate is expected to decline and monetary policy, in turn, to react to this by lowering the nominal interest rate far enough. This mechanism has been described in detail earlier in the analytical example of Section 3.

A notable consequence of the reduced government debt is an overshooting of consumption following the lift-off of the nominal interest rate from the ZLB. It is exactly the expectations of such overshooting and underlying low real interest rates that made the reduction of government debt optimal because of its stimulative effect on private demand. The overshooting is small but persistent, which is explained by a relatively strong desire to smooth it over time. The relative strength of the time-smoothing motive makes the convergence of government debt back to the steady state very slow. In particular, the half-life of debt recovery following the peak of decline is equal to 30.5 years.

\subsection{The Role of the Initial Debt Level}

The dynamic response of the economy studied above assumes initial debt equal to the risky steady-state level. Figure 4 generalizes previous analysis by considering a range of initial debt levels. It shows one-period responses to the negative demand shock of three unconditional standard deviations (black solid lines) and the demand shock equal to the unconditional average (dashed blue lines). The responses are plotted as functions of initial debt valued using the market price in the deterministic steady state and measured as a fraction of annual output in the deterministic steady state. Consumption, output, and government spending are reported in terms of percentage deviations from the deterministic steady state. Inflation and the interest rates are reported in annualized percentages. The labor tax rate is reported as a deviation from the deterministic steady-state value in percentage points. Government debt is reported as a difference between initial condition and the end-of-period debt

finding in Erceg and Lindé (2014) that an exogenous increase in government spending may be self-financing and not require a build-up of government debt in a liquidity trap. 
valued using the market price in the deterministic steady state and measured as a fraction of annual output in the deterministic steady state.

[Figure 4 about here.]

According to the figure, the qualitative nature of the response of fiscal variables to a negative demand shock that makes the ZLB binding does not change for a wide range of initial levels of government debt. Government spending conditional on the negative demand shock is higher than government spending conditional on the unconditional average demand. So is the tax rate. Importantly, government debt declines in response to the negative demand shock. The sensitivity analysis performed below will demonstrate the role of maturity in shaping the response of government debt.

\section{$5 \quad$ Sensitivity Analyses}

This section analyzes the sensitivity of results with respect to the maturity of government debt and the risk of reaching the ZLB.

\subsection{The Maturity of Government Debt}

The analytical analysis in Section 3 suggested that the maturity of government debt is likely to be crucial in shaping the response of government debt in a liquidity trap. The current subsection, therefore, performs the quantitative exercise by changing the structure of government debt from long-term debt to one-period bonds. Figure 5 shows an impulse response of the modified model starting from the risky steady state and hit by the negative demand shock of three unconditional standard deviations. The response shows conditional dynamics in the absence of shocks in the future and the units of variables are as before.

The response of government spending remains stimulative: rising on impact and gradually reverting back to the steady state. Notably, the response of government spending is stronger in the economy with one-period debt. On 
impact the increase in government spending is eight times larger than in the baseline case with long-term debt.

[Figure 5 about here.]

The responses of the tax rate and government debt, however, exhibit qualitative changes in the economy with one-period debt. The labor income tax is reduced below the steady state in the beginning and only later raised above it. Government debt displays a hump-shaped response starting with an increase and followed by a reversal to the steady state. Thus, the direction of government debt response is the opposite of that in the economy with long-term debt. The persistence of government debt also changes: the reversal of government debt becomes faster with the half-life declining to seven quarters.

The response described above is consistent with the findings in models with one-period government debt studied by Eggertsson (2006) and Burgert and Schmidt (2014). One can therefore see that the prescription of deficitfinanced government spending in the liquidity trap previously found in the literature relied heavily on the assumption of short-term structure of government debt. This assumption, however, is at odds with the data on the duration of government debt in the advanced countries.

It is also worth mentioning that the risky steady state and the underlying risk of a liquidity trap differ in the economy with one-period debt. The third column in Table 3 reports the risky steady state. It shows that the market value of government debt measured as a fraction of annual output is 6 percentage points lower than in the economy with long-term debt. Part of this difference is likely explained by the lower implied probability of being at the ZLB, which is equal to 16 percent in the economy with one-period debt. The next subsection provides additional evidence on the link between the risk of a liquidity trap and the risky steady-state level of government debt.

\subsection{The Risk of a Liquidity Trap}

The quantitative analysis in Section 4 showed that the risk of reaching the ZLB makes it optimal for a government to accumulate more debt in the steady 
state. The current subsection provides additional evidence on the sensitivity of debt accumulation to the underlying risk. In particular, it considers the case with a lower risk of a liquidity trap.

Table 3 - Sensitivity of the Risky Steady State

\begin{tabular}{llll}
\hline \multirow{2}{*}{ Variable } & \multicolumn{3}{c}{ Risky } \\
\cline { 2 - 4 } & Baseline & $\rho=0$ & $\sigma=0.30$ \\
\hline Output gap & -0.11 & -0.01 & -0.04 \\
Inflation & 0.045 & 0.015 & 0.014 \\
Nominal interest rate & 2.25 & 2.28 & 2.48 \\
Market value of debt & 53 & 47 & 44 \\
Labor tax rate & 17.54 & 17.40 & 17.41 \\
Government spending & 20 & 20 & 20 \\
\hline
\end{tabular}

Notes: Output gap is a relative difference from the deterministic steady state. Inflation and the nominal interest rate are in annual percentages. Market value of debt is in percentages relative to annual output. Spending is in percentages relative to output.

The baseline model with long-term debt is changed by setting $\sigma=0.30$ to reduce the variance of demand shocks by 25 percent. The implied probability of reaching the ZLB goes down to 15 percent - the reduction by almost 50 percent. The fourth column in Table 3 reports the corresponding risky steady state. The market value of government debt measured as a fraction of annual output is 9 percentage points lower than in the baseline case. It is also 4 percentage points above the deterministic steady state. One can therefore see that the effect of risk on the accumulation of government debt is nonlinear. Moreover - taken together with the result in the previous subsection - the same risk of reaching the ZLB might be associated with different magnitudes of debt accumulation depending on the maturity structure of debt. 


\section{Conclusion}

This paper characterizes optimal monetary and fiscal policy under discretion in a model with nominal rigidities where the ZLB occasionally binds following an adverse aggregate demand shock. The key innovation of this paper is to allow for government debt with long maturity in line with the one observed in the data across advanced economies. This paper shows that long-run government debt increases with the risk of reaching the ZLB. Moreover, once a strong demand shock hits and makes the ZLB binding, it is optimal for the government to temporarily reduce debt.

The main contribution of this paper is to show that accumulating debt during a liquidity trap may or may not be optimal depending on its maturity. While existing studies show that it is desirable to increase debt in an economy with short-term bonds, the analysis in the current paper shows the opposite if the model is calibrated to match the observed maturity of government's liabilities.

The importance of government debt maturity for the results in this paper encourages further research on revisiting conventional monetary-fiscal policy prescriptions depending on the maturity of government debt and, furthermore, incorporating debt management consideration into optimal policy design. Additionally, the analysis in this paper assumes a perfectly competitive labor market and flexible wages. An important avenue for future research would be to explore the effects of labor market imperfections on optimal policy. 


\section{References}

Adam, K., Billi, R., 2007. Discretionary Monetary Policy and the Zero Lower Bound on Nominal Interest Rates. Journal of Monetary Economics 54 (3), 728-752. 4, 5

Bernanke, B., 2016. Monetary Policy in the Future. In: Blanchard, O., Rajan, R., Rogoff, K., Summers, L. H. (Eds.), Progress and Confusion: The State of Macroeconomic Policy. The MIT Press, pp. 129-134. 3

Bhattarai, S., Eggertsson, G., Gafarov, B., 2015. Time Consistency and the Duration of Government Debt: A Signalling Theory of Quantitative Easing. NBER Working Paper No. 21336. 5

Burgert, M., Schmidt, S., 2014. Dealing with a Liquidity Trap When Government Debt Matters: Optimal Time-Consistent Monetary and Fiscal Policy. Journal of Economic Dynamics and Control 47, 282-299. 3, 5, 13, 19, 20, 29

Calvo, G., 1983. Staggered Prices in a Utility-Maximizing Framework. Journal of Monetary Economics 12 (3), 383-398. 21

Clarida, R., Galí, J., Gertler, M., 1999. The Science of Monetary Policy: A New Keynesian Perspective. Journal of Economic Literature 37 (4), 1661-1707. 4

Coeurdacier, N., Rey, H., Winant, P., 2011. The Risky Steady-State. The American Economic Review 101 (3), 398-401. 22

Currie, J., Wilson, D., 2012. Opti: Lowering the Barrier between Open Source Optimizers and the Industrial MATLAB User. In: Sahinidis, N., Pinto, J. (Eds.), Foundations of Computer-Aided Process Operations. Savannah, Georgia, USA. 40

Debortoli, D., Nunes, R., 2012. Lack of Commitment and the Level of Debt. Journal of the European Economic Association 11 (5), 1053-1078. 4

Eggertsson, G., 2006. The Deflation Bias and Committing to Being Irresponsible. Journal of Money, Credit and Banking 38 (2), 283-321. 3, 5, 19, 29 
Eggertsson, G., Woodford, M., 2006. Optimal Monetary and Fiscal Policy in a Liquidity Trap. In: Clarida, R. H., Frankel, J., Giavazzi, F., West, K. D. (Eds.), NBER International Seminar on Macroeconomics 2004. The MIT Press, pp. 75-144. 3, 4, 20, 26

Erceg, C., Lindé, J., 2014. Is There a Fiscal Free Lunch in a Liquidity Trap? Journal of the European Economic Association 12 (1), 73-107. 27

Greenwood, R., Hanson, S., Rudolph, J., Summers, L., 2014. Government Debt Management at the Zero Lower Bound. Hutchins Center Working Paper \#5. 3,21

Kiley, M. T., Roberts, J. M., 2017. Monetary Policy in a Low Interest Rate World. Brookings Papers on Economic Activity 48 (1), 317-396. 25

Leith, C., Wren-Lewis, S., 2013. Fiscal Sustainability in a New Keynesian Model. Journal of Money, Credit and Banking 45 (8), 1477-1516. 13

Lucas, R., Stokey, N., 1983. Optimal Fiscal and Monetary Policy in an Economy without Capital. Journal of Monetary Economics 12 (1), 55-93. 3

Matveev, D., 2016. Monetary Policy and Government Debt Dynamics without Commitment. Working Paper. 5, 19

Nakata, T., 2016. Optimal Fiscal and Monetary Policy with Occasionally Binding Zero Bound Constraints. Journal of Economic Dynamics and Control $73,220-240.5$

Nakata, T., 2017. Optimal Government Spending at the Zero Lower Bound: A Non-Ricardian Analysis. Review of Economic Dynamics 23, 150-169. 3, 4, 20,26

Nakov, A., 2008. Optimal and Simple Monetary Policy Rules with Zero Floor on the Nominal Interest Rate. International Journal of Central Banking 4 (2), $73-127.4,5$ 
Schmidt, S., 2013. Optimal Monetary and Fiscal Policy with a Zero Bound on Nominal Interest Rates. Journal of Money, Credit and Banking 45 (7), 1335-1350. 4, 5, 26

Werning, I., 2011. Managing a Liquidity Trap: Monetary and Fiscal Policy. NBER Working Paper No. 17344. 4, 26

Woodford, M., 2001. Fiscal Requirements for Price Stability. Journal of Money, Credit and Banking 33 (3), 669-728. 7 


\section{A Appendix}

\section{A.1 The First-Best Allocation}

The Lagrangian corresponding to the social planner problem is

$$
L \equiv \mathbb{E}_{0} \sum_{t=0}^{\infty} \beta^{t} \xi_{t}\left[u\left(c_{t}\right)+g\left(G_{t}\right)-v\left(h_{t}\right)+\gamma_{t}\left(h_{t}-c_{t}-G_{t}\right)\right]
$$

The first-order conditions with respect to $\left(c_{t}, G_{t}, h_{t}\right)$ are as follows:

$$
\begin{aligned}
& u^{\prime}\left(C_{t}\right)=\gamma_{t}, \\
& g^{\prime}\left(G_{t}\right)=\gamma_{t}, \\
& v^{\prime}\left(Y_{t}\right)=\gamma_{t} .
\end{aligned}
$$

Eliminating the Lagrange multiplier $\gamma_{t}$ leaves the system with two equations:

$$
\begin{aligned}
& 0=g^{\prime}\left(G_{t}\right)-u^{\prime}\left(c_{t}\right), \\
& 0=g^{\prime}\left(G_{t}\right)-v^{\prime}\left(h_{t}\right),
\end{aligned}
$$

which together with the resource constraint $h_{t}=c_{t}+G_{t}$ characterize the first-best allocation. 


\section{A.2 The Policy Problem}

The Markov-Perfect equilibrium is associated with a solution to the following Bellman equation:

$$
\mathcal{V}\left(s_{t}\right)=\max _{\left(c_{t}, y_{t}, \pi_{t}, w_{t}, q_{t}, b_{t}, G_{t}, \tau_{t}\right)}\left[u\left(c_{t}\right)+g\left(G_{t}\right)-v\left(y_{t}\right)\right]+\beta d_{t} \mathbb{E}_{t}\left\{\mathcal{V}\left(s_{t+1}\right)\right\}
$$

subject to

$$
\begin{aligned}
0 & =c_{t}+G_{t}-y_{t}\left(1-\frac{1}{2} \varphi\left(\pi_{t}-1\right)^{2}\right), \\
0 & =\left(1-\tau_{t}\right) w_{t}-\frac{v^{\prime}\left(y_{t}\right)}{u^{\prime}\left(c_{t}\right)}, \\
0 & =q_{t}-\beta d_{t} \mathbb{E}_{t}\left\{\frac{\left(1+\rho Q\left(s_{t+1}\right)\right) u^{\prime}\left(\mathcal{C}\left(s_{t+1}\right)\right)}{\Pi\left(s_{t+1}\right) u^{\prime}\left(c_{t}\right)}\right\}, \\
0 & =(1-s) w_{t}-\frac{(\theta-1)}{\theta} \\
& \quad-\frac{\varphi}{\theta}\left(\pi_{t}\left(\pi_{t}-1\right)-\beta d_{t} \mathbb{E}_{t}\left\{\frac{u^{\prime}\left(\mathcal{C}\left(s_{t+1}\right)\right)}{u^{\prime}\left(c_{t}\right)} \frac{\mathcal{Y}\left(s_{t+1}\right)}{y_{t}} \Pi\left(s_{t+1}\right)\left(\Pi\left(s_{t+1}\right)-1\right)\right\}\right), \\
0 & =q_{t} b_{t}-\left(\frac{1+\rho q_{t}}{\pi_{t}}\right) b_{t-1}-G_{t}+\tau_{t} w_{t} y_{t}-s\left(w_{t} y_{t}-\bar{w} \bar{y}\right), \\
1 \leqslant & \frac{u^{\prime}\left(c_{t}\right)}{\beta d_{t}}\left(\mathbb{E}_{t}\left\{\frac{u^{\prime}\left(\mathcal{C}\left(s_{t+1}\right)\right)}{\Pi\left(s_{t+1}\right)}\right\}\right)^{-1} .
\end{aligned}
$$

This is a dynamic functional problem, and its solution consists of a value function $\mathcal{V}$ and decision rules $(\mathcal{C}, \mathcal{Y}, \Pi, \mathcal{W}, \mathcal{Q}, \mathcal{B}, \mathcal{G}, \mathcal{T})$ that determine the underlying private-sector equilibrium in every period of time as a function of the payoff-relevant state, $s_{t} \equiv\left(b_{t-1}, d_{t}\right)$, as in $c_{t}=\mathcal{C}\left(s_{t}\right), y_{t}=\mathcal{Y}\left(s_{t}\right)$, etc. To ease the exposition, two variables are eliminated from the system of privatesector equilibrium conditions using two of its equations. These variables are employment, $h_{t}$, and the nominal interest rate, $R_{t}$, whereas the corresponding equations are the aggregate production function equation (2.8) and the Euler equation (2.5). Decision rules for the former, $\mathcal{H}\left(b_{t-1}\right)$ and $\mathcal{R}\left(b_{t-1}\right)$, are recovered using the latter, given the solution of the Bellman equation above. 


\section{A.3 Analysis of the Deterministic Steady States}

To analyze deterministic steady states of the Markov-Perfect equilibrium set $\sigma=0, d_{t}=1$ for all $t \geqslant 0$. Let bars over variables denote deterministic steadystate values. For example, the vector of state variables at a deterministic steady state is denoted as $\bar{s}=(\bar{b}, 1)$. The analysis below is restricted to interior deterministic steady states where the ZLB is not binding.

In order to detect and classify the steady states one can use a generalized Euler equation. This equation is an optimality condition characterizing the Markov-Perfect equilibrium derived by taking a first-order condition with respect to government debt and then using the Envelope theorem to substitute for the derivative of the value function. At a deterministic steady state this equation reads as

$$
\bar{\Delta}_{b} \bar{\Omega}=0
$$

where

$$
\begin{aligned}
\bar{\Omega} & =\frac{\varphi(\bar{\pi}-1) \bar{y}}{\varphi(\bar{\pi}-1) \bar{y}+\frac{\varphi}{\theta}(2 \bar{\pi}-1) \bar{y}+\left(1+\rho q_{t}\right) \frac{\bar{b}}{\bar{\pi}^{2}}}, \\
\bar{\Delta}_{b}= & \frac{\varphi}{\theta}\left(\frac{\bar{\pi}}{1+\rho \bar{q}}\right)\left(-\bar{\pi}(\bar{\pi}-1)\left(\frac{\mathcal{C}^{\prime}(\bar{b}) u^{\prime \prime}(\bar{c})}{u^{\prime}(\bar{c})} \bar{y}+\mathcal{Y}^{\prime}(\bar{b})\right)-\Pi^{\prime}(\bar{b})(2 \bar{\pi}-1) \bar{y}\right) \\
& -\left(\frac{\Pi^{\prime}(\bar{b})}{\bar{\pi}}-\frac{\mathcal{C}^{\prime}(\bar{b}) u^{\prime \prime}(\bar{c})}{u^{\prime}(\bar{c})}-\frac{\rho \mathcal{Q}^{\prime}(\bar{b})}{1+\rho \bar{q}}\right)\left(1-\frac{\rho}{\bar{\pi}}\right) \bar{b}
\end{aligned}
$$

Equation (A.1) implies that there are two types of possible deterministic steady states. In the first steady state, where $\bar{\Omega}=0$, inflation is zero, i.e., $\bar{\pi}=1$. In the second steady state, where $\bar{\Delta}_{b}=0$, a marginal change of government debt does not provide any gains from affecting next-period decisions. The remainder of this section characterizes further the deterministic steady state of the first type.

The remaining optimality conditions characterizing the Markov-Perfect equilibrium at the steady state with zero inflation read as 


$$
\begin{aligned}
& 0=\bar{c}+\bar{G}-\bar{y} \\
& 0=(1-\bar{\tau}) \bar{w}-\frac{v^{\prime}(\bar{y})}{u^{\prime}(\bar{c})}, \\
& 0=\bar{q}-\beta(1+\rho \bar{q}) \\
& 0=\bar{w}-\frac{\theta-1}{(1-s) \theta}, \\
& 0=\bar{q} \bar{b}-(1+\rho \bar{q}) \bar{b}-\bar{G}+\bar{\tau} \bar{w} \bar{y} \\
& 0=g^{\prime}(\bar{G})-u^{\prime}(\bar{c}), \\
& 0=g^{\prime}(\bar{G})-v^{\prime}(\bar{y}) .
\end{aligned}
$$

Equations (A.2)-(A.8) implicitly determine steady-state values $(\bar{c}, \bar{y}, \bar{w}, \bar{q}, \bar{b}, \bar{G}, \bar{\tau})$. Furthermore, the steady-state values of employment and the nominal interest rate are recovered by evaluating at the steady state the aggregate production function equation (2.8) and the Euler equation (2.5):

$$
\begin{aligned}
& \bar{h}=\bar{y} \\
& \bar{R}=\beta^{-1} .
\end{aligned}
$$

Equations (A.2), (A.7), (A.8) and (A.9) imply that this steady state is efficient, that is consistent with the first-best allocation.

Furthermore, combining equations (A.7) and (A.8) results in the following condition:

$$
0=1-\frac{v^{\prime}(\bar{y})}{u^{\prime}(\bar{c})}
$$

which, together with equation (A.3), yields condition $1=(1-\bar{\tau}) \bar{\omega}$, where the tax rate and the real wage can be further substituted for using equations (A.4)-(A.6) so as to get

$$
1=\frac{\theta-1}{(1-s) \theta}-\frac{\bar{G}}{\bar{y}}-\left(\frac{1-\beta}{1-\beta \rho}\right) \frac{\bar{b}}{\bar{y}} .
$$

The steady-state levels of government spending and output, $\bar{G}$ and $\bar{y}$, are 
determined independently of equation (A.11). Therefore, equation (A.11) implicitly determines the steady-state level of government debt, $\bar{b}$, as a function of the rate of employment subsidy, $s$.

Note that a simplified version of the model with inflation-indexed government debt features the same efficient steady state. This follows directly from a fact that conditions of the private-sector equilibrium with nominal and inflation-indexed debt are isomorphic whenever inflation is zero.

\section{A.4 Quadratic Approximation of Welfare}

This section of the appendix shows how to derive a quadratic approximation of the household's welfare in a simplified version of the model where government spending is assumed to be constant and equal to the first-best level.

Let the household's period $t$ utility be defined as

$$
U_{t} \equiv \xi_{t}\left(\frac{c_{t}^{1-\gamma_{c}}}{1-\gamma_{c}}+\nu_{g} \frac{\bar{G}^{1-\gamma_{g}}}{1-\gamma_{g}}-\nu_{h} \frac{h_{t}^{1+\gamma_{h}}}{1+\gamma_{h}}\right) .
$$

In order to derive accurate approximation of welfare that preserves ranking of the government policy alternatives when maximizing subject to (log-)linearized private-sector equilibrium conditions, one can substitute for consumption in the period $t$ utility using the resource constraint (2.9) and substitute employment with output using the aggregate production function (2.8):

$$
\tilde{U}_{t} \equiv \xi_{t}\left(\frac{\left(y_{t}\left(1-\frac{\varphi}{2}\left(\pi_{t}-1\right)^{2}\right)-\bar{G}\right)^{1-\gamma_{c}}}{1-\gamma_{c}}+\nu_{g} \frac{\bar{G}^{1-\gamma_{g}}}{1-\gamma_{g}}-\nu_{h} \frac{y_{t}^{\gamma_{h}+1}}{1+\gamma_{h}}\right)
$$

Next, a variable change in (A.12) is made by substituting original variables with their log-deviations from the efficient deterministic steady state, where hats are used to denote log-deviations. Formally, the following identity is used for a generic variable $X_{t}$ :

$$
X_{t}=\bar{X} e^{\hat{X}_{t}}, \quad \text { where } \hat{X}_{t} \equiv \ln X_{t}-\ln \bar{X} \text {. }
$$


The resulting expression is then approximated to the second-order using Taylor expansion around the efficient deterministic steady state as follows:

$$
\tilde{U}_{t} \simeq-\frac{1}{2} \bar{c}^{-\gamma_{c}} \bar{y}\left(\left(\tilde{\gamma}_{c}+\gamma_{h}\right) \hat{y}_{t}^{2}+\varphi \hat{\pi}_{t}^{2}\right)+\text { t.i.p. }
$$

where $\tilde{\gamma}_{c} \equiv \gamma_{c}(\bar{y} / \bar{c})$, t.i.p. stands for terms independent of policy, and policydependent linear terms have been eliminated using the steady-state conditions (A.2), (A.7) and (A.8).

As a result, the household's welfare can be approximated (up to additive terms independent of policy) by

$$
-\frac{1}{2} \mathbb{E}_{0} \sum_{t=0}^{\infty} \beta^{t}\left(\frac{\tilde{\gamma}_{c}+\gamma_{h}}{\varphi} \hat{y}_{t}^{2}+\hat{\pi}_{t}^{2}\right) .
$$

\section{A.5 Nonlinear Solution Method}

The model is solved using the value function iteration to search for a fixed point of the value function and the corresponding decision rules. Starting with a guess of the next-period value function and future decision rules, one can solve the optimization problem of the government in a single period on a discretized state space. The new solution is then used to update guesses of the value function and the decision rules. The procedure is repeated until reaching a convergence when the value function and the decision rules in the two consecutive iterations become arbitrarily close. The value function and the decision rules off the grid points are interpolated using cubic splines. Expectations are computed using Gauss-Hermite quadrature.

The method is implemented in Matlab using IPOPT, an open source nonlinear optimization solver. IPOPT is interfaced for Matlab in the freeware third-party OPTI toolbox; see Currie and Wilson (2012) for a description. Computation speed is improved by parallelizing the step of solving the optimization problem on the grid. 
Figure 1 - Impulse Response without the ZLB
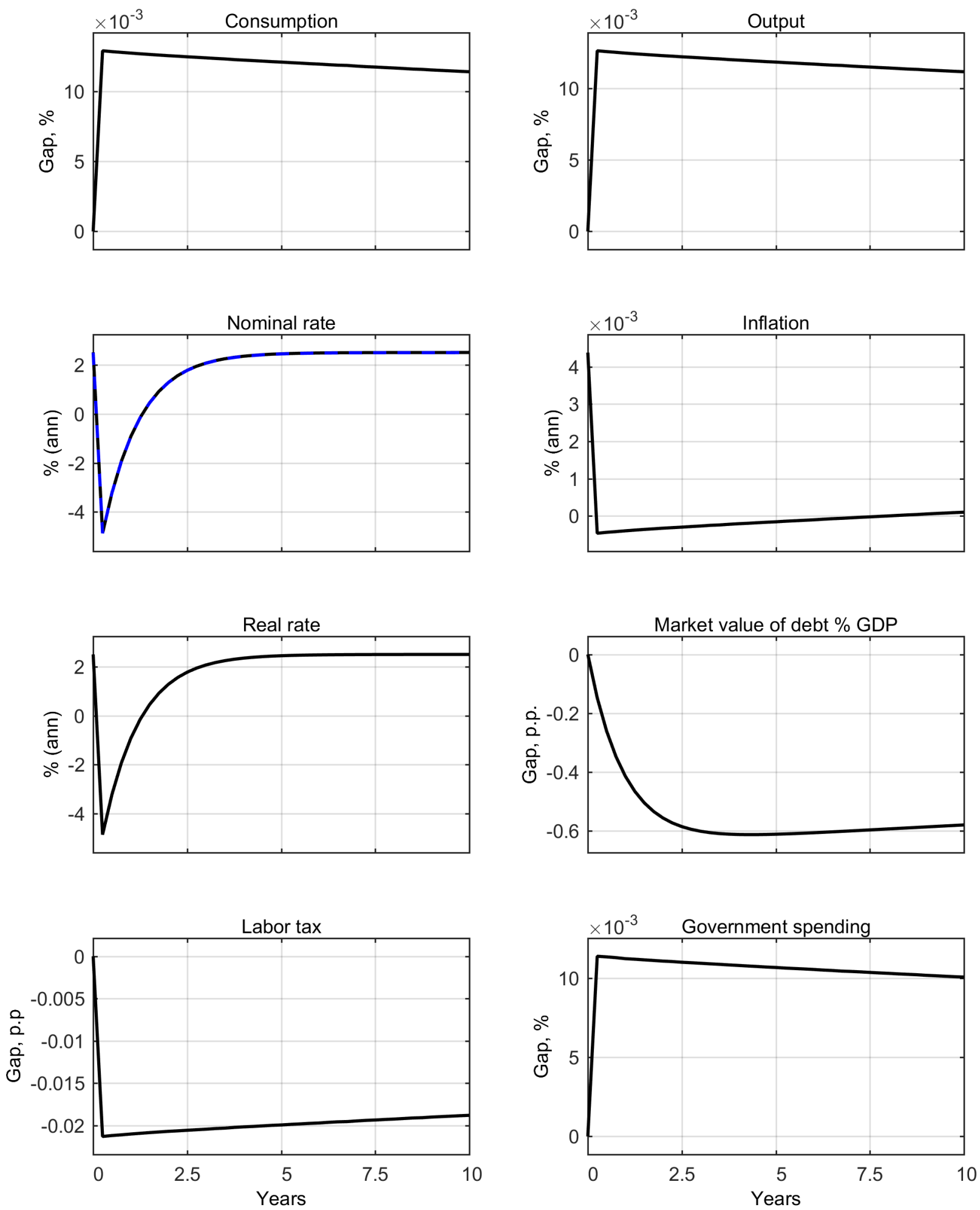

Notes: Impulse response to a negative demand shock of three unconditional standard deviations on impact starting from the risky steady state and assuming no further shocks. Dashed blue line corresponds to the rate of time preference. 
Figure 2 - Conditional Equilibrium Decision Rules
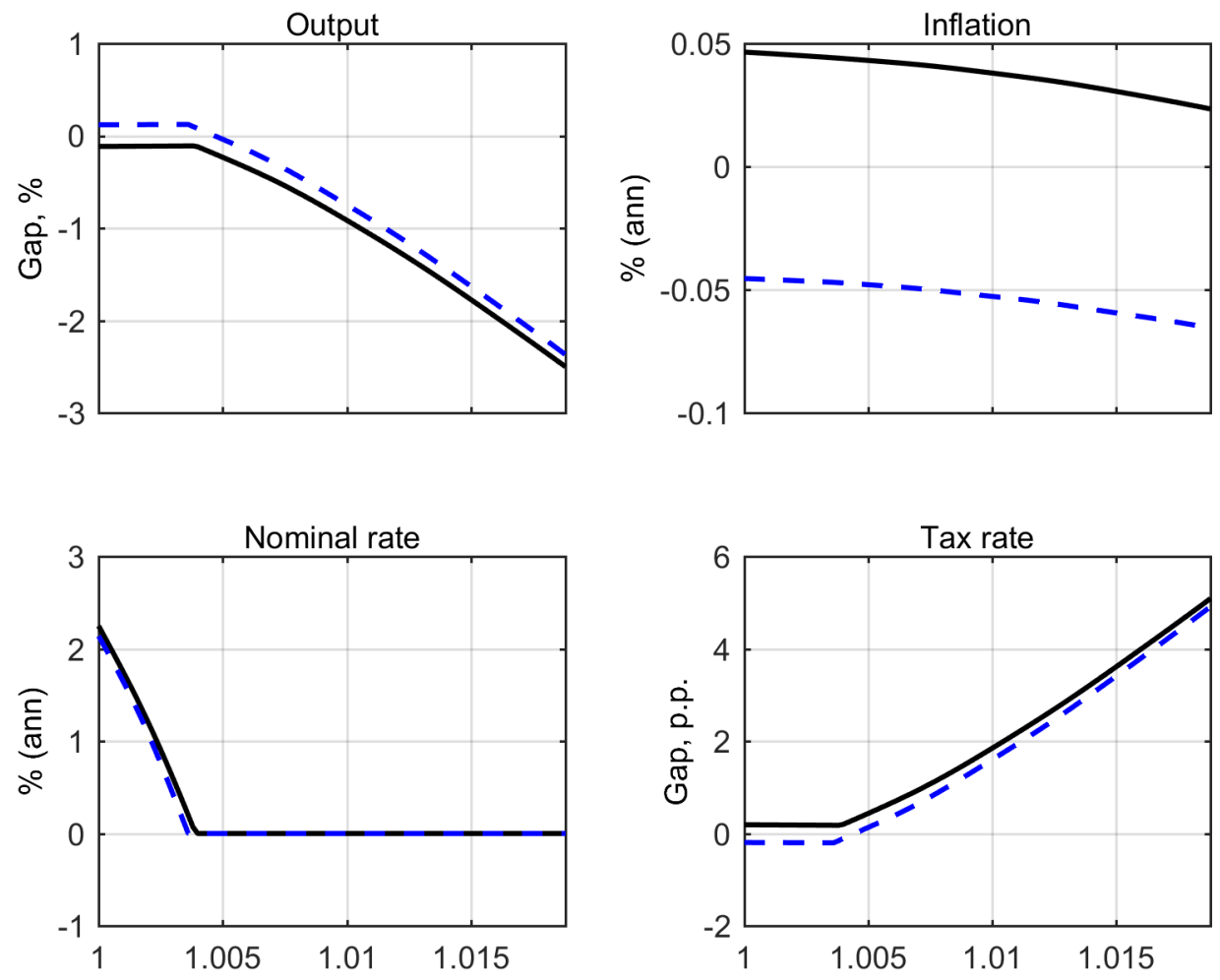

Notes: Equilibrium decision rules conditional on the initial value of government debt. Horizontal axes display demand shock values. Solid black lines: initial debt equal to the risky steady-state value. Dashed blue lines: initial debt equal to the deterministic steady-state value. 
Figure 3 - Impulse Response with the ZLB
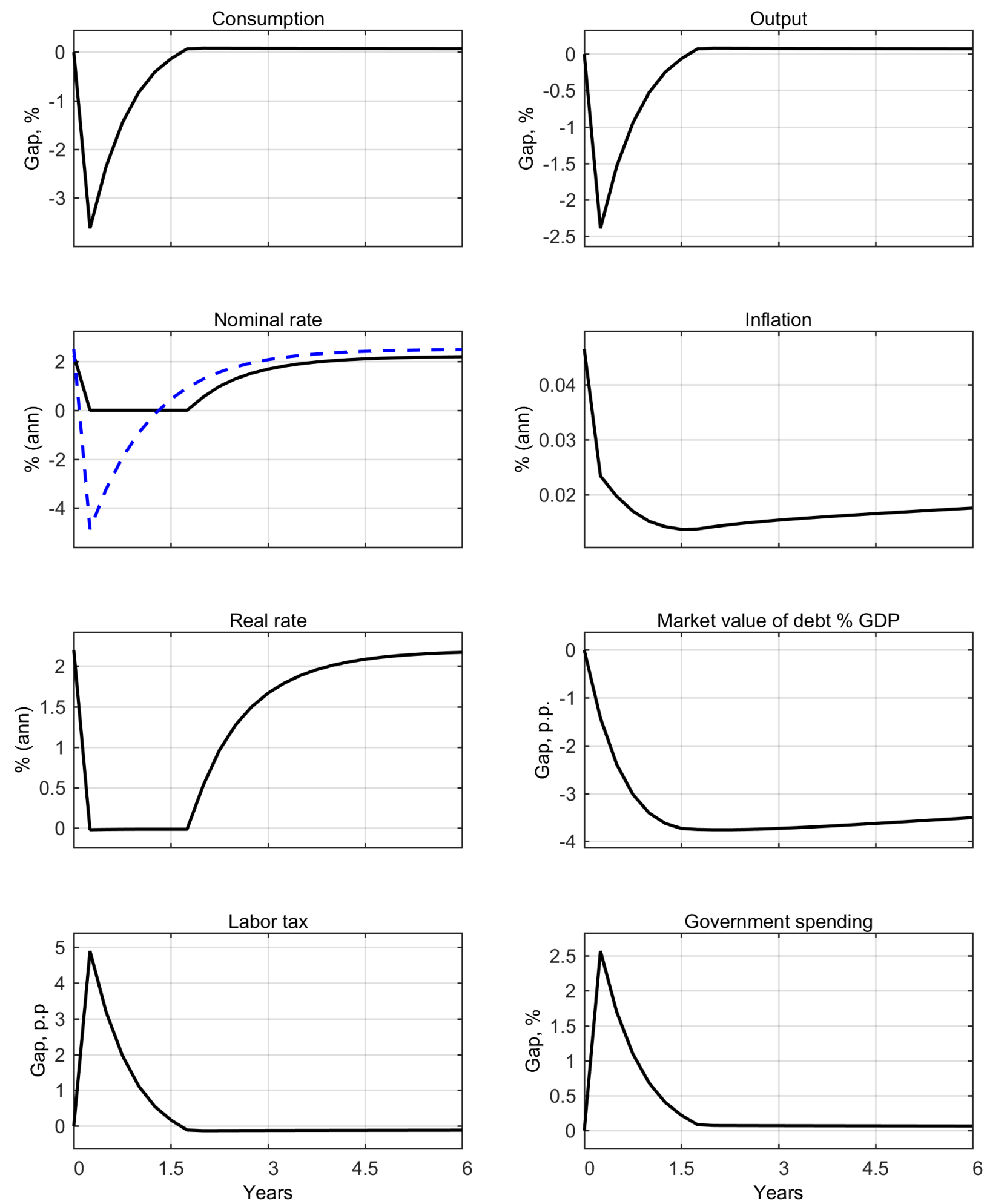

Notes: Impulse response to a negative demand shock of three unconditional standard deviations on impact starting from the risky steady state and assuming no further shocks. Dashed blue line corresponds to the rate of time preference. 
Figure 4 - Conditional Equilibrium Decision Rules
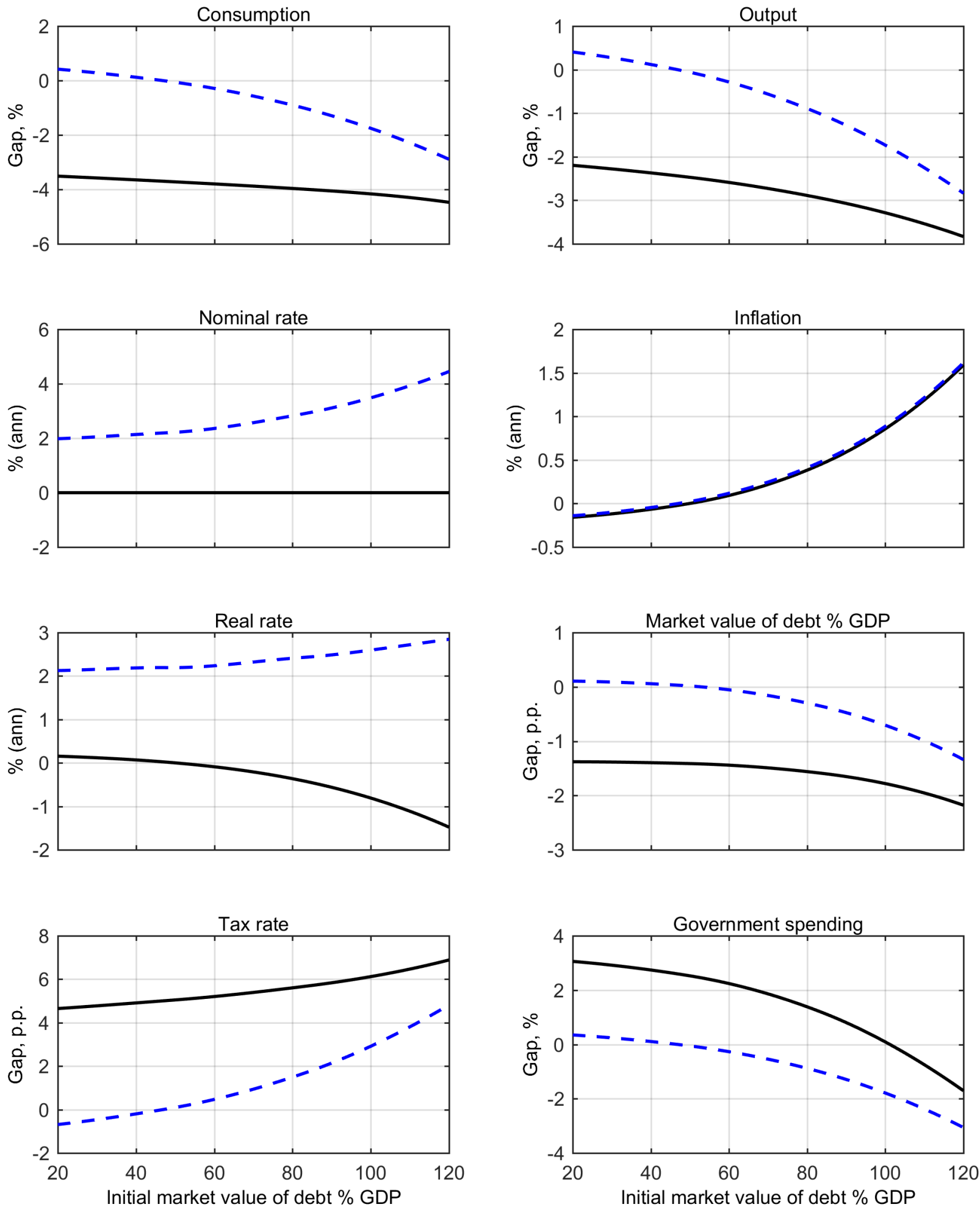

Notes: Equilibrium decision rules conditional on the demand shock realization. Solid black lines: a negative demand shock of three unconditional standard deviations. Dashed blue lines: a demand shock equal to the unconditional average. 
Figure 5 - Impulse Response with One-period Debt
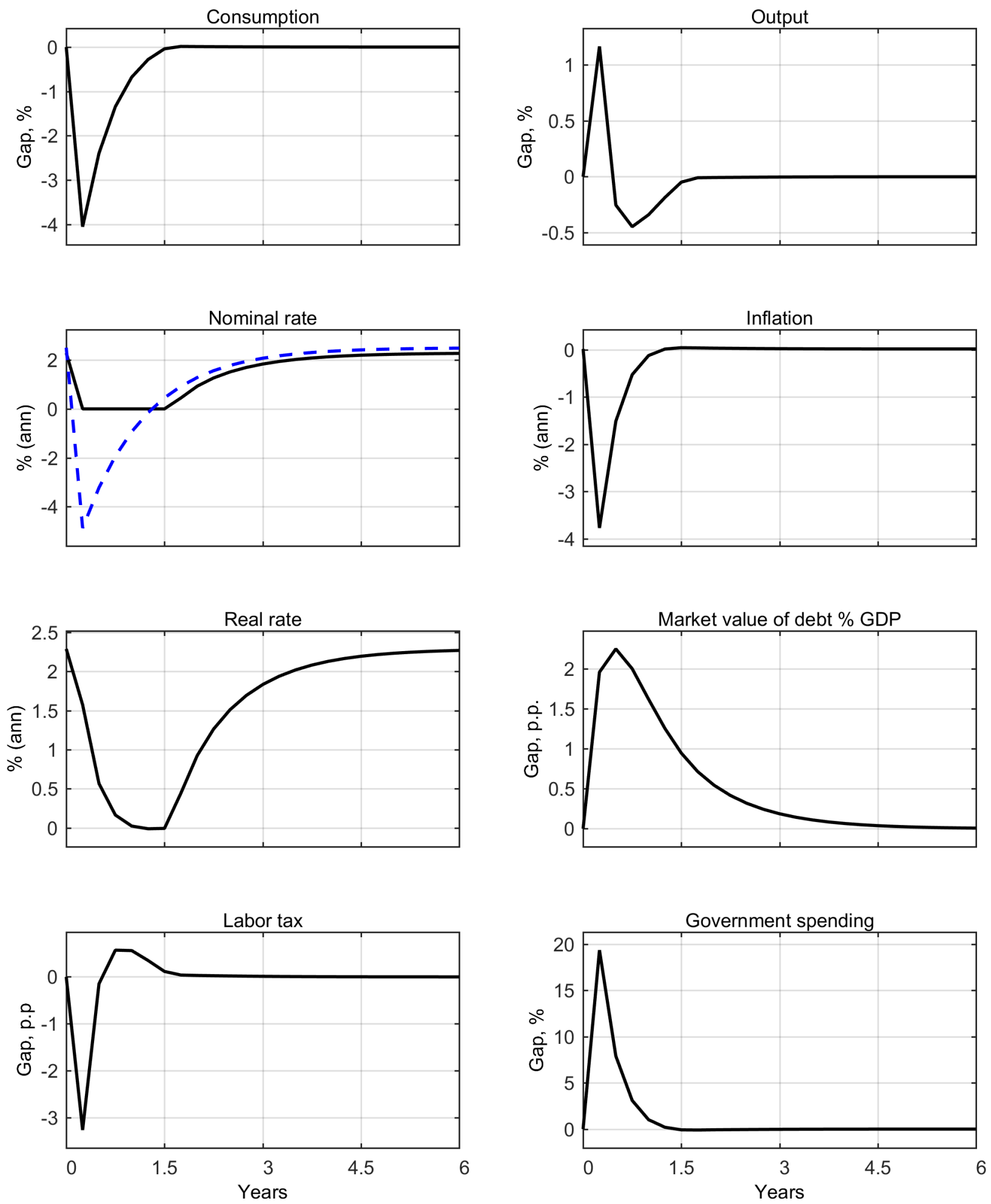

Notes: Impulse response to a negative demand shock of three unconditional standard deviations on impact starting from the risky steady state and assuming no further shocks. Dashed blue line corresponds to the rate of time preference. 